Original Research

\title{
Differences in pain and function between adolescent athletes and physically active non-athletes with patellofemoral pain
}

\author{
Amanda Schenatto Ferreira ${ }^{a}$, Danilo de Oliveira Silva ${ }^{\text {a, b }}$, Liliam Barbuglio Del Priore ${ }^{\text {a }}$, \\ Carmen Lucia Gomes Garcia ${ }^{\text {a }}$, Matheus Henrique Maiolini Ducatti ${ }^{\text {a }}$, \\ Ana Flavia Balotari Botta ${ }^{a}$, Marina Cabral Waiteman ${ }^{a}$, Fábio Mícolis de Azevedo a, * \\ ${ }^{a}$ Laboratory of Biomechanics and Motor Control (LABCOM), School of Science and Technology, São Paulo State University (UNESP), Presidente Prudente, Sao \\ Paulo, Brazil \\ ${ }^{\mathrm{b}}$ La Trobe Sports and Exercise Medicine Research Centre (LASEM), School of Allied Health, La Trobe University, Bundoora, Victoria, Australia
}

\section{A R T I C L E I N F O}

\section{Article history:}

Received 21 May 2018

Received in revised form

3 July 2018

Accepted 10 July 2018

\section{Keywords:}

Knee

Anterior knee pain

Adolescents

Physical function

\begin{abstract}
A B S T R A C T
Objectives: To investigate pain level and function limitation in adolescent athletes and physically active non-athletes with PFP.

Design: Cross-sectional study.

Setting: Adolescent athletes were recruited at a sport center complex. Adolescent non-athletes were recruited from upper secondary schools.

Participants: 108 adolescents diagnosed with PFP: 42 adolescent athletes and 66 adolescent nonathletes.

Main outcome measures: To evaluate the level of pain, a visual analog scale (VAS) was used and to evaluate the overall function, the Knee Outcome in Osteoarthritis Survey (KOOS) was used.

Results: The adolescent athletes scored significantly higher in the VAS (Mean difference $=0.97(95 \%$ $\mathrm{CI}=0.35$; 1.60) $\mathrm{p}=0.003$ ) compared to adolescent non-athletes. Adolescent athletes scored lower in the KOOS - Symptoms, Pain, Knee-related quality of life and Sport and recreation dimensions - than the nonathletes, however, the minimally clinically important difference was not achieved in Pain dimension. There was no significant difference in the Activities of daily living dimension of the KOOS.

Conclusions: Adolescent athletes presented higher levels of pain and lower physical function status compared with physically active non-athletes. This provides an important insight to the management of PFP in adolescent athletes as worst functional status is linked with poor prognosis in patients with PFP.
\end{abstract} (C) 2018 Published by Elsevier Ltd

\section{Introduction}

An estimated 12 million physical active people aged 5-22 suffer at least one sport injury every year, generating spends of approximately $\$ 33$ billion in healthcare worldwide (Valovich McLeod et al., 2009). The knee is the most frequently injured joint among adolescents aged 13-19 (Louw, Manilall, \& Grimmer, 2008; Witvrouw, Lysens, Bellemans, Cambier, \& Vanderstraeten, 2000). Knee disorders reach $33 \%$ in this population, with patellofemoral pain (PFP) representing 7\% of the total (Kinga et al., 2011). PFP in adolescence can decrease physical activity levels and lead to disability (Rathleff,

\footnotetext{
* Corresponding author. Rua Roberto Simonsen, 305, Presidente Prudente, SP, Brazil.
}

E-mail address: fabio.micolis@fct.unesp.br (F.M. de Azevedo).
2016; Utting, Davies, \& Newman, 2005), moreover, evidence suggest that patellofemoral osteoarthritis may be a progression of PFP (Crossley, 2014; Utting et al., 2005).

The onset of PFP has been related with increased levels of physical activity (Fairbank, Pynsent, van Poortvliet, \& Phillips, 1984). The increase in the level of physical activity can lead to a chronic overloading and temporary overuse of the patellofemoral joint (PFJ), contributing to the development of PFP symptoms (Tállay et al., 2004). This occurs especially in activities which require a great amount of knee flexion and consequently generate increased compressive forces on the PFJ, such as those performed in some sports activities (e.g. basketball, volleyball, handball and soccer) (Foss, Hornsby, Edwards, Myer, \& Hewett, 2012; Nejati, Forogh, Moeineddin, Baradaran, \& Nejati, 2011). Accordingly, a study (Barber Foss, Myer, \& Hewett, 2014) reported that PFP is the 
Table 1

Details of the sports performed by the adolescent athletes.

\begin{tabular}{|c|c|c|c|c|}
\hline Sport & Number of participants (\% of the total sample) & Training frequency (days per week) & Training session duration (hours) & Game frequency (days per week) \\
\hline Basketball & $11(26 \%)$ & 5 & 3 & 1 \\
\hline Handball & $9(21.5 \%)$ & 4 & 2 & 1 \\
\hline Soccer & $12(28.5 \%)$ & 4 & 4 & 1 \\
\hline Volleyball & $10(24 \%)$ & 4 & 3 & 1 \\
\hline
\end{tabular}

most common injury among middle-school female athletes who practice sports activities that flex the knee regularly, with a incidence of $26.1 \%$ in basketball, $33.3 \%$ in soccer and $42.1 \%$ in volleyball.

It is well established that professional adolescent athletes differ in question of explosive power, aerobic capacity and neuromuscular control from those non-athletes (Boonstra, Preuper, Reneman, Posthumus, \& Stewart, 2008; Del Percio et al., 2007). In addition, sports training in high-intensities can be responsible for excessive loads on PFJ (Nejati et al., 2011), which could exacerbate the condition and it is often suggested as a possible contributor to the development of PFP (Myer et al., 2010). Thus, professional adolescent athletes and non-athletes could present discrepancies in relation to first episode of knee pain, functional limitations and pain level related to their level of sports practice. This is an important issue to be clarified, as worst functional status and duration of symptoms are linked with poor prognosis in PFP, both 1 year and 5-8 years after treatment (Collins et al., 2008). In addition, adults with PFP presented lower levels of physical activity compared to pain-free individuals, such finding reinforces that PFP could affect adolescent's life in the near future (Glaviano, Baellow, \& Saliba, 2017).

In this context, the aim of this study is to investigate if there are differences in pain level and function limitation in adolescent athletes and physically active non-athletes with PFP, due to the strong relationship to these outcomes with the prognosis of PFP. Our hypothesis is that adolescent athletes will present higher levels of pain and lower physical function status compared with non-athletes. Our hypothesis is based on the rationale that repetitive sports training may excessively load the PFJ, contributing to symptoms exacerbation, and consequently, to function limitations.

\section{Methods}

\subsection{Participants}

This was a cross-sectional study comparing adolescent athletes and non-athletes aged 12-18 diagnosed with PFP. We recruited 108 participants between June 2015 and January 2016. The group of adolescent athletes ( $\mathrm{N}=42 ; 31$ Males and 11 Females) were recruited via athletic trainer and coach contacts at a sport center complex. The athletes were regularly involved in training and competition activities of basketball, volleyball, handball and soccer, which are sports where high loads are constantly applied in a flexed knee. All athletes were assessed at the middle of the season. The details of each sport performed by the adolescent athletes are presented in Table 1 . Adolescent non-athletes $(\mathrm{N}=66 ; 31$ Males and 35 Females) were recruited from six upper secondary schools. In order to ensure the homogeneity of the sample, only participants involved in recreational physical activities were included in the non-athletes group. To be classified as physically active, the participants had to fulfilling the short form of the International Physical Activity Questionnaire (IPAQ-S). The two criteria used for classification as physically active were: a) vigorous activity at least 3 days per week, or b) moderate activity at least 5 days per week (International Physical Activity Questionnaire, 2005). In order to obtain the sample of this study, we screened 130 adolescent athletes (total population of adolescent athletes available at the sports centers complex of the region) and 311 adolescent non-athletes (the maximum number of adolescents that was possible to assess in the schools). Therefore, the rate of adolescent athletes and nonathletes with PFP corresponded to $32.3 \%$ and $21.2 \%$, respectively (Fig. 1). We included a higher number of adolescent non-athletes as compared with athletes (due to the higher number of non-athletes
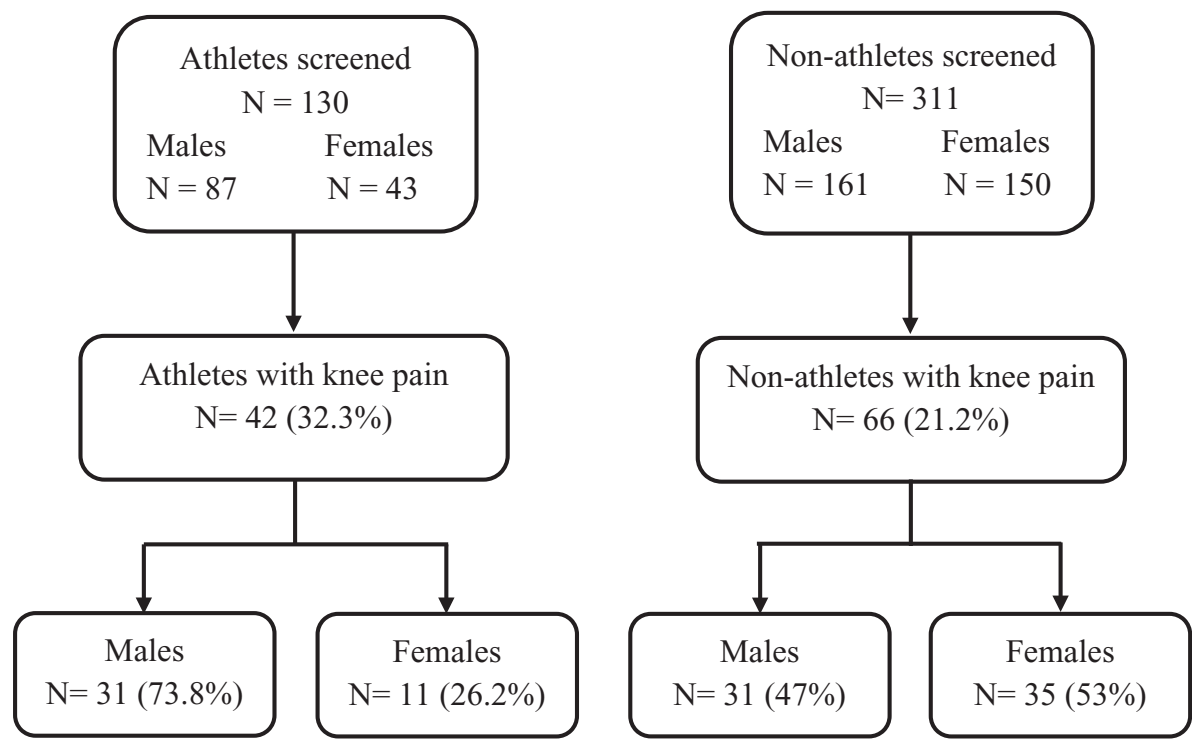

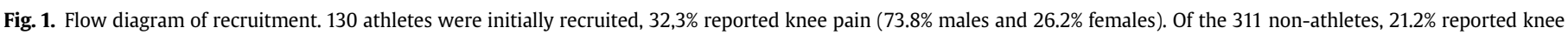
pain (47\% males and $53 \%$ females). 


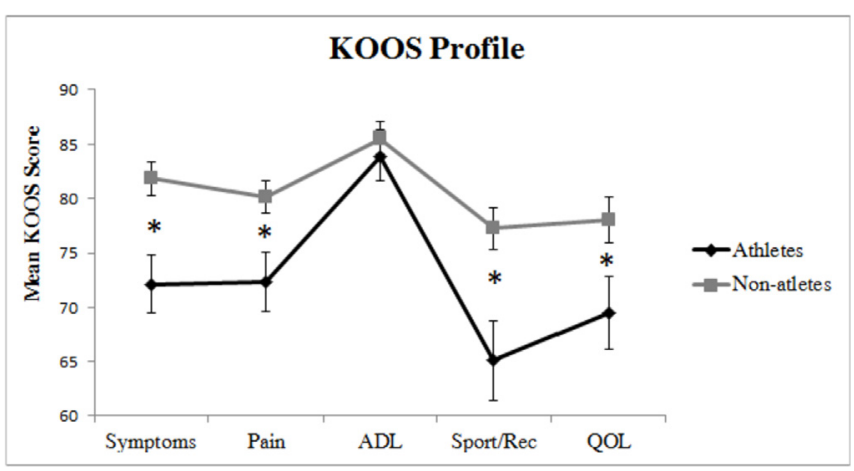

Fig. 2. Mean and standard deviations of KOOS scores in adolescent athletes and nonathletes with PFP. *Represents significant differences between groups for KOOS score in the dimensions of Symptoms, Pain, Sport/Rec and QOL. ADL = Activities of daily living. Sport $/ \operatorname{Rec}=$ Sport and recreation function. $\mathrm{QOL}=$ Knee-related quality of life.

that could be screened initially).

Adolescents of both groups were diagnosed with PFP if they met the following criteria (Ferreira et al., 2018; Rathleff, Rathleff, Olesen, Rasmussen, \& Roos, 2016): insidious onset of anterior knee or retropatellar pain for at least the past 6 weeks; pain provoked by at least 2 of the following activities: prolonged sitting or kneeling, squatting, running, or stair walking; tenderness on palpation of the anterior surface of the patella; and worst pain intensity in the previous month of at least $3 \mathrm{~cm}$ on a $10 \mathrm{~cm}$ visual analog scale (VAS) (Rathleff et al., 2013). Exclusion criteria were assessed by a licensed physiotherapist ( $>5$ years of experience in clinical practice). Exclusion criteria: concomitant injury or pain from the hip, lumbar spine, or other knee structures; previous knee surgery; patellofemoral instability; knee joint effusion; use of physiotherapy for treating knee pain within the previous year; currently undergoing medical treatment; or daily or weekly use of anti-inflammatory drugs. Participants of the group of non-athletes were excluded if involved in sports competition (Roos, Roos, Lohmander, Ekdahl, \& Beynnon, 1998).

The study was approved by the Local Human Ethics Committee (number: 037518/2015). Before completing the survey, the participants' parent or guardian signed an informed consent form with the participant's agreement.

\subsection{Outcome measures}

Participants' usual pain in the previous month was measured with a VAS, which is a reliable and valid tool for this purpose (Boonstra et al., 2008; Chesworth, Culham, Tata, \& Peat, 1989; Crossley, Bennell, Cowan, \& Green, 2004). The VAS consisted of a $10-\mathrm{cm}$ horizontal line, the beginning of line represents no pain ( 0 $\mathrm{cm})$ and the end represents extreme pain $(10-\mathrm{cm})$ (Powers, Perry, Hsu, \& Hislop, 1997).

The overall function of the participants was evaluated with the Knee Outcome in Osteoarthritis Survey (KOOS). The KOOS was constructed on the basis of the literature review and expert panel (Roos et al., 1998), it is a 42-item questionnaire that covers five dimensions reported separately: pain, symptoms, activities of daily living (ADL), sport and recreation function (Sport/Rec), and kneerelated quality of life (QOL). Each item can be scored from 0 to 4 Likert scale and the scores were transformed to a 0-100 scale, with zero representing extreme knee problems and 100 representing no knee problems (Van de Graaf, Wolterbeek, Scholtes, Mutsaerts, \& Poolman, 2014).

Physical activity level of the participants was obtained by the short, self-administered version of the IPAQ. The questionnaire provided information about the time spent walking, in vigorous and moderate intensity activity and in sedentary activity, which are used to estimate total weekly physical activity as metabolic equivalent (MET) expressed as MET-minutes.week ${ }^{-1}$ (Craig et al., 2003; International Physical Activity Questionnaire, 2005).

\subsection{Procedures}

All participants were asked to rate their knee pain on a VAS during the initial assessment. They were required to draw a mark along a $10 \mathrm{~cm}$ line indicating the usual amount of knee pain they had felt in the previous month. The mark indicates the intensity of pain and this is converted to a numerical value (Boonstra et al., 2008). Then, participants completed self-administered questionnaires: KOOS and IPAQ-S. The surveys were administered in a classroom (non-athletes group) or at the sport center complex (athletes group) and they spent approximately $30 \mathrm{~min}$ to complete the questionnaires. The participants were assisted by a trained physiotherapist. Participants were also asked to rate the duration of their PFP symptoms (months).

\subsection{Statistical analysis}

Statistical analyses were performed using the Statistical Package for Social Sciences (SPSS) version 18.0 (SPSS Inc., Chicago IL) with an a priori level of significance of $\alpha<0.05$. Normality. Descriptive statistics for sample characteristics were expressed using mean (standard deviation). To determine the normality and homogeneity of the data, Shapiro-Wilk's and Levene's tests were used, respectively (Field, 2013). The characteristics of the participants, physical activity levels, usual pain VAS and all five dimensions of the KOOS were compared between groups using independent $t$ tests. The minimum clinically important difference (MCID), which represents the smallest change in a measurement outcome that patients value as important, was reported for each dimension of the KOOS and VAS. Previous studies indicated that a change of 8-10 points in each dimension of the KOOS (Roos \& Lohmander, 2003) and a change of $1.5 \mathrm{~cm}$ in VAS for usual pain (Crossley et al., 2004) is required to reflect real change in patient symptoms. Effect sizes (ES) were calculated using Review Manager (RevMan) (Version 5.3., Copenhagen, Denmark) and the guidelines for interpreting ES values are: small $(>0.2)$, medium $(>0.5)$, large $(>0.8)$, and very large (>1.3) (Sullivan \& Feinn, 2012).

\section{Results}

No significant differences between the groups for body mass, age, height and duration of the symptoms were found. Adolescent athletes with PFP presented significantly higher physical activity levels than adolescent non-athletes with PFP (Mean difference $=3675.79 \quad \mathrm{MET} \cdot \mathrm{min} \cdot \mathrm{wk}-1 \quad[95 \% \mathrm{CI}=950.231 ; \quad 6654.342]$ $\mathrm{p}<0.001)$ and a very large magnitude of difference was identified between groups $(\mathrm{ES}=1.66[95 \% \mathrm{CI}=1.21 ; 2.11])$.

Compared with non-athletes with PFP, athletes with PFP scored significantly higher in the VAS (Mean difference $=0.97 \mathrm{~cm}[95 \%$ $\mathrm{CI}=0.35 ; 1.60] \mathrm{p}=0.003$ ) with a medium magnitude of difference between groups ( $\mathrm{ES}=0.61[95 \% \mathrm{CI}=0.21 ; 1.00]$ ); however, the MCID for patients with PFP $(1.5 \mathrm{~cm}$ in a $10-\mathrm{cm}$ VAS for usual pain (Crossley et al., 2004)) was not achieved (Table 2).

\section{Discussion}

Pain levels and function limitations were explored in adolescent athletes and physically active non-athletes with PFP. Our findings demonstrated that adolescent athletes have higher levels of pain 
Table 2

Demographic data for both groups.

\begin{tabular}{|c|c|c|c|}
\hline Variables & Adolescent Athletes Mean (SD) & Adolescents Non-athletes Mean (SD) & p-value \\
\hline Age (years) & $15.04(1.79)$ & $14.78(1.64)$ & 0.354 \\
\hline Body Mass (kg) & $64.21(14.35)$ & $57.83(9.85)$ & 0.195 \\
\hline Height $(\mathrm{m})$ & $1.72(0.11)$ & $1.65(0.08)$ & 0.221 \\
\hline Physical activity level $\left(\right.$ MET $\left.\cdot \min \cdot \mathrm{wk}^{-1}\right)$ & $7848.19(2440.54)$ & $4172.40(2031.07)$ & $<0.001$ \\
\hline Usual pain in the last month (VAS) & $5.31(1.59)$ & $4.33(1.63)$ & 0.003 \\
\hline Symptoms duration (Months) & $21.05(22.95)$ & $15.05(14.74)$ & 0.129 \\
\hline
\end{tabular}

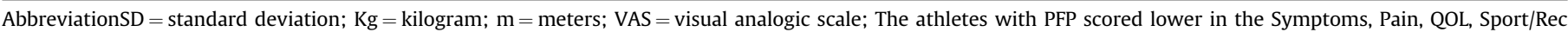

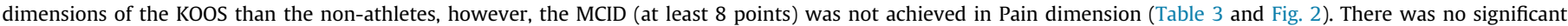
difference in the ADL dimension of the $\operatorname{KOOS}(\mathrm{p}=0.53)$

Table 3

Distribution of KOOS scores and MCID.

\begin{tabular}{lllll}
\hline KOOS & Mean Difference $(95 \% \mathrm{CI})$ & $\mathrm{t}_{(=106)}$ & $\mathrm{p}$-value & Effect size $(95 \% \mathrm{CI})$ \\
\hline Symptoms & $-9.69(-15.46 ;-3.93)$ & 3.33 & 0.001 & $-0.65(-1.05 ;-0.26)$ \\
Pain & $-7.82(-13.61 ;-2.02)$ & 2.67 & 0.009 & $-0.53(-0.92 ;-0.13)$ \\
ADL & $-1.57(-6.1 ; 3.45)$ & 0.62 & 0.536 & $-0.12(-0.51 ; 0.27)$ \\
Sport/Rec & $-12.15(-19.64 ;-4.66)$ & 3.21 & 0.002 & $-0.63(-1.03 ;-0.23)$ \\
QOL & $-8.53(-15.96 ;-1.10)$ & 2.27 & 0.025 & $-0.45(-0.84 ;-0.05)$ \\
\hline
\end{tabular}

$95 \% \mathrm{CI}=$ Confidence interval at $95 \%$ percentile. Abbreviation: $\mathrm{ADL}=$ Activities of daily living. Sport $/ \mathrm{Rec}=$ Sport and recreation function. $\mathrm{QOL}=$ Knee-related quality of life.

and function limitations than physically active non-athletes. These findings indicate that be engaged in professional sports practice may be related to high levels of pain and poor function in adolescents with PFP.

Fairbank et al., 1984, reported an association between high levels of daily pain and increased physical activity practiced by adolescents with PFP. According to the authors (Fairbank et al., 1984), the greater mechanical demand on lower limbs generated by the practice of physical activity may be the cause of knee pain exacerbation. Our findings corroborate with this assumption as athletes with PFP, usually exposed to greater mechanical demands compared to physically active non-athletes, presented higher levels of pain in both VAS and KOOS - Pain dimension measures. However, it must be acknowledged that differences regarding pain levels did not reach the MCID (Crossley et al., 2004; Roos \& Lohmander, 2003). A reasonable explanation for this finding is that we included physically active non-athletes with PFP and, despite not being athlete, this group of participants was exposed to a high level of physical activity $(4172.40 \pm 2031.07 \mathrm{MET} \cdot \mathrm{min} \cdot \mathrm{wk}-$ 1). According to IPAQ-S scoring criteria they were classified into the high physical activity level category (Dyrstad, Hansen, Holme, \& Anderssen, 2014; International Physical Activity Questionnaire, 2005), which could have resulted in a minor difference of knee pain between groups. Therefore, further research is now needed to identify the level of pain presented by sedentary and moderately active adolescents with PFP, which could be clinically lower than athletes and physically activity non-athletes with PFP. Also, athletes with PFP were assessed at the middle of the season. It is plausible to hypothesize that evaluating athletes at the end of the season may indicate cumulative effect of the PFJ overload that athletes are exposed and its impact on knee pain. Such hypothesis is supported by Herbst et al., 2015 who reported a high incidence of PFP in adolescent basketball players at the end of the season.

Although both athletes and non-athletes' groups can be classified as highly active, the adolescent athletes with PFP presented with higher levels of physical activity. The very large magnitude of difference between groups (effect size $=1.66$ ) reinforces the idea that adolescent athletes with PFP are exposed to a greater mechanical demand. In this direction, Myer et al., 2010 reported that the prevalence of PFP in adolescent athletes at the beginning of the season was 16.3 per 100 athletes and increased to 22.0 per 100 athletes along the competitive season period. Although recreational physical activities also can stress the PFJ (De Oliveira Silva et al., 2015), the prevalence of overtraining in professional athletes has been reported between 20 and 60\% (Peluso \& Andrade, 2005). These facts may be a reflection of training routine with high loads and intense training rhythm (high mechanical demand) that lead to increased PFJ stress, recognized as the major problem of PFP (Powers, Bolgla, Callaghan, Collins, \& Sheehan, 2012; Witvrouw et al., 2014), which could contribute to worse pain and function prognosis (Lankhorst et al., 2016).

Functional status is of utmost importance as it predicts the prognosis of patients with PFP. Lankhorst et al., 2016, reported in their prospective study that the better the functional status the better the prognosis of patients with PFP. Our findings demonstrate that adolescent athletes with PFP presented poorer functional status than physically active non-athletes in almost all KOOS' dimensions, except for ADL. This finding may suggest that managing training loads according to symptoms could be an important issue to be considered by clinicians responsible for sports teams to reduce symptom aggravation of adolescent athletes with PFP (Lack, Neal, De Oliveira Silva, \& Barton, 2018). Accordingly, Rathleff, Roos, Olesen, \& Rasmussen, 2015, demonstrated that an exercise therapy associated with patient' load management education had long term (24 months) positive effect on reducing pain and improve overall function in adolescents with PFP. However, an individual-based prescription should be aimed when treating or assessing patients with PFP regardless their age (Glaviano \& Saliba, 2016). Regarding non-significant findings in ADL, it is important to elucidate that the ADL dimension contains items that do not represent challenging activities (e.g. squatting, kneeling), such activities might not be challenging enough to exacerbate pain and lead to functional limitations in a population of adolescents. However, with regard to other dimensions (e.g. running, jumping) higher levels of pain and exacerbation of symptoms have been reported during high-intense physical activity practice (Lankhorst, Bierma-Zeinstra, \& van Middelkoop, 2013) and it reflects in poor outcomes in sports functionality and quality of life related to the knee, as demonstrated by our study.

The impact of sport-related injury on adolescent's QOL remains an issue that has been barely investigated in the field of sports medicine. Our findings demonstrated that adolescent athletes with PFP presented lower QOL related to the knee than physical active adolescents with PFP. These findings corroborate with those reported by Cheung, Zhang, \& Ngai, 2013, in which professional athletes reported lower QOL than amateur athletes. Injuries in athletes result in high health care costs and impose a significant physiological and psychosocial health impact (Valovich McLeod et al., 2009). Psychosocial examination is an important component of a sports injury appraisal as reduced QOL due to knee pain may demotivate the participation in professional sports activities (Cheung et al., 2013). Considering our findings, it seems that 
clinicians should be aware that reports of pain and overall subjective function may be different in adolescents with PFP who have different levels of physical activity. Therefore, the quantification and consideration of physical activity levels is essential during assessment and development of a treatment strategy for adolescent athletes with PFP.

\subsection{Clinical impact and applicability of findings}

Adolescents diagnosed with PFP continue to report pain and symptoms over the years (Stathopulu \& Baildam, 2003) and, as a consequence, have high potential for a chronicity (Rathleff et al., 2016) and possible future development of patellofemoral osteoarthritis (Utting et al., 2005). Besides progression to more severe orthopaedic disorders, PFP in adolescence is known to reduce participation in sports and general physical activities (Stathopulu \& Baildam, 2003; Waiteman et al., 2017). The reduction or cessation in sports practices have implications of serious concern, as it leads to consequences on the overall health during adolescence and later in adulthood (e.g. obesity, cardiorespiratory diseases) (Myer et al., 2014). In this direction, health-professionals responsible for teams need to consider the pain and functional limitations presented by athletes during training schedule. The adoption of strategies to prevent or early-treatment of adolescents with PFP should be developed. Myer et al., 2015, reported that the use of exercises interventions and retraining of the sport gesture may reduce risk factors for PFP. Also, recent studies focusing on load management education to modify PFJ loading have been shown to improve pain and function of individuals with PFP (Esculier et al., 2018; Rathleff et al., 2015). In addition, other interventions such as counseling from sports psychologists should also be considered as part of the management, aiming to enhance the overall QOL in adolescents with PFP. One of the biggest challenges is to understand the needs of adolescents, they should be actively enrolled in the treatment decision-making. In the future, the elaboration of preventive interventions could reduce the proportion of adolescents, both athletes and physically active non-athletes, who develop severe knee pain.

\subsection{Limitations}

Some limitations of this study should be acknowledged, (i) the group of athletes with PFP was not evaluated separately in each sports modality, which could provide a certain level of bias as different sports practices may lead to different levels of stress on the PFJ; (ii) as we only assessed athletes who were regularly involved in training and competition, this could possibly exclude athletes with more severe symptoms as they may be restrained from sports; (iii) we could not investigate potential mechanical differences between athletes and physical activity non-athletes with PFP, further research is now needed to investigate the underlying reasons for the differences reported in pain and function limitations; (iv) a high amount of male athletes could be initially screened due to complex sport center availability, thus it was probably the reason for the presence of more males in the group of athletes with PFP compared to the group of physical activity nonathletes; ( $v$ ) in light of gender differences identified in previous studies with adolescents and adults with PFP, the use of a disproportionate mixed-gender sample may be a confounder of our results, therefore, further gender-specific investigations are warranted to confirm findings of the present study.

\section{Conclusion}

Adolescent athletes with PFP presented higher levels of pain and lower physical function status compared with physically activity non-athletes with PFP. These findings highlight the need for further investigations in the specific population of adolescent athletes which practice high levels of physical activity in both prevention and treatment level.

\section{Declaration of interest}

None.

\section{Conflicts of interest}

None declared.

\section{Funding}

This research did not receive any specific grant from funding agencies in the public, commercial, or not-for-profit sectors.

\section{Ethical approval}

The study was approved by the São Paulo State University Ethics Committee (number: 037518/2015).

\section{Acknowledgments}

São Paulo Research Foundation (FAPESP) for a scholarship, authors: ASF (2016/02357-1).

\section{References}

Boonstra, A. M., Preuper, S.,H. R., Reneman, M. F., Posthumus, J. B., \& Stewart, R. E. (2008). Reliability and validity of the visual analogue scale for disability in patients with chronic musculoskeletal pain. International Journal of Rehabilitation Research, 31(2), 165-169. https://doi.org/10.1097/MRR.0b013e3282fc0f93.

Chesworth, B. M., Culham, E. G., Tata, E. G., \& Peat, M. (1989). Validation of outcome measures in patients with patellofemoral syndrome. Journal of Orthopaedic \& Sports Physical Therapy, 10(8), 302-308.

Cheung, R. T. H., Zhang, Z., \& Ngai, S. P. C. (2013). Different relationships between the level of patellofemoral pain and quality of life in professional and amateur athletes. Physical Medicine and Rehabilitation, 5(7), 568-572. https://doi.org/10. 1016/j.pmrj.2012.12.007.

Collins, N., Crossley, K., Beller, E., Darnell, R., McPoil, T., \& Vicenzino, B. (2008). Foot orthoses and physiotherapy in the treatment of patellofemoral pain syndrome: Randomised clinical trial. British Medical Journal, 337, a1735. https://doi.org/10. 1136/bmj.a1735.

Craig, C. L., Marshall, A. L., Sjöström, M., Bauman, A. E., Booth, M. L. Ainsworth, B. E.,... Oja, P. (2003). International physical activity questionnaire: 12-Country reliability and validity. Medicine \& Science in Sports \& Exercise, 35(8), 1381-1395. https://doi.org/10.1249/01.MSS.0000078924.61453.FB.

Crossley, K. M. (2014). Is patellofemoral osteoarthritis a common sequela of patellofemoral pain? British Journal of Sports Medicine, 48(6), 409-410. https://doi org/10.1136/bjsports-2014-093445.

Crossley, K. M., Bennell, K. L., Cowan, S. M., \& Green, S. (2004). Analysis of outcome measures for persons with patellofemoral pain: Which are reliable and valid? Archives of Physical Medicine and Rehabilitation, 85(5), 815-822. https://doi.org/ 10.1016/S0003-9993(03)00613-0.

De Oliveira Silva, D., Briani, R., Pazzinatto, M., Ferrari, D., Aragão, F. \& Azevedo, F. (2015). Vertical ground reaction forces are associated with pain and selfreported functional status in recreational athletes with patellofemoral pain. Journal of Applied Biomechanics, 31(6), 409-414. https://doi.org/10.1123/jab. 2015-0048.

Del Percio, C., Brancucci, A., Vecchio, F., Marzano, N., Pirritano, M. Meccariello, E., ... Eusebi, F. (2007). Visual event-related potentials in elite and amateur athletes. Brain Research Bulletin, 74(1-3), 104-112. https://doi.org/10. 1016/j.brainresbull.2007.05.011.

Dyrstad, S. M., Hansen, B. H., Holme, I. M., \& Anderssen, S. A. (2014). Comparison of self-reported versus accelerometer-measured physical activity. Medicine \& Science in Sports \& Exercise, 46(1), 99-106. https://doi.org/10.1249/MSS Ob013e3182a0595f.

Esculier, J.-F., Bouyer, L. J., Dubois, B., Fremont, P., Moore, L., McFadyen, B., et al. (2018). Is combining gait retraining or an exercise programme with education better than education alone in treating runners with patellofemoral pain?A randomised clinical trial. British Journal of Sports Medicine, 52(10), 659-666. https://doi.org/10.1136/bjsports-2016-096988. 
Fairbank, J. C., Pynsent, P. B., van Poortvliet, J. A., \& Phillips, H. (1984). Mechanica factors in the incidence of knee pain in adolescents and young adults. The Journal of Bone and Joint Surgery, 66(5), 685-693. Retrieved from: http://www. ncbi.nlm.nih.gov/pubmed/6501361.

Ferreira, A. S., De Oliveira Silva, D., Briani, R. V., Ferrari, D., Aragão, F. A., Pazzinatto, M. F., et al. (2018). Which is the best predictor of excessive hip internal rotation in women with patellofemoral pain: Rearfoot eversion or hip muscle strength? Exploring subgroups. Gait \& Posture, 62(March), 366-371. https://doi.org/10.1016/j.gaitpost.2018.03.037.

Field, A. (2013). Discovering statistics using IBM SPSS Statistics (4th ed.). SAGE Publications Ltd.

Foss, K. D. B., Hornsby, M., Edwards, N. M., Myer, G. D., \& Hewett, T. E. (2012). Is body composition associated with an increased risk of developing anterior knee pain in adolescent female athletes? The Physician and Sportsmedicine, 40(1), 13-19. https://doi.org/10.3810/psm.2012.02.1947.

Foss, B. K. D., Myer, G. D., \& Hewett, T. E. (2014). Epidemiology of basketball, soccer, and volleyball injuries in middle-school female athletes. The Physician and Sportsmedicine, 42(2), 146-153. https://doi.org/10.3810/psm.2014.05.2066. Epidemiology.

Glaviano, N. R., Baellow, A., \& Saliba, S. (2017). Physical activity levels in individuals with and without patellofemoral pain. Physical Therapy in Sport, 27, 12-16. https://doi.org/10.1016/j.ptsp.2017.07.002.

Glaviano, N. R., \& Saliba, S. (2016). Impairment based rehabilitation for patellofemoral pain patients. The Physician and Sportsmedicine, 44(3), 311-323. https:/ doi.org/10.1080/00913847.2016.1200443.

Herbst, K. A., Barber Foss, K. D., Fader, L., Hewett, T. E., Witvrouw, E., Stanfield, D. et al. (2015). Hip strength is greater in athletes who subsequently develop patellofemoral pain. The American Journal of Sports Medicine, 43(11), 2747-2752. https://doi.org/10.1177/0363546515599628.

International Physical Activity Questionnaire. (2005). Guidelines for Data Processing and Analysis of the International Physical Activity Questionnaire (IPAQ) - Short and Long Forms. International Physical Activity Questionnaire (IPAQ), (November), 1-15. Retrieved from: http://www.ipaq.ki.se/scoring.pdf.

Kinga, S., Chambers, C. T., Huguet, A., MacNevin, R. C., McGrath, P. J., Parker, L, et al. (2011). The epidemiology of chronic pain in children and adolescents revisited: A systematic review. The Journal of the International Association for the Study of Pain, 152(12), 2729-2738. https://doi.org/10.1016/j.pain.2011.07.016.

Lack, S., Neal, B., De Oliveira Silva, D., \& Barton, C. (2018). How to manage patellofemoral pain - understanding the multifactorial nature and treatment options. Physical Therapy in Sport, 32, 155-166. https://doi.org/10.1016/j.ptsp.2018. 04.010.

Lankhorst, N. E., Bierma-Zeinstra, S. M. A., \& van Middelkoop, M. (2013). Factors associated with patellofemoral pain syndrome: A systematic review. British Journal of Sports Medicine, 47(4), 193-206. https://doi.org/10.1136/bjsports2011-090369.

Lankhorst, N. E., van Middelkoop, M., Crossley, K. M., Bierma-Zeinstra, S. M. A. Oei, E. H. G., Vicenzino, B., et al. (2016). Factors that predict a poor outcome 5-8 years after the diagnosis of patellofemoral pain: A multicentre observationa analysis. British Journal of Sports Medicine, 50(14), 881-886. https://doi.org/10 1136/bjsports-2015-094664.

Louw, Q. A., Manilall, J., \& Grimmer, K. A. (2008). Epidemiology of knee injuries among adolescents: A systematic review. British Journal of Sports Medicine, 42(1), 2-10. https://doi.org/10.1136/bjsm.2007.035360.

Myer, G. D., Faigenbaum, A. D., Foss, K. D. B., Xu, Y., Khoury, J. Dolan, L. M., ... Hewett, T. E. (2014). Injury initiates unfavourable weight gain and obesity markers in youth. Sports Medicine, 48(20), 1477-1481. https://doi. org/10.1136/bjsports-2012-091988.Injury.

Myer, G. D., Ford, K. R., Barber Foss, K. D., Goodman, A., Ceasar, A Rauh, M. J., ... Hewett, T. E. (2010). The incidence and potential pathomechanics of patellofemoral pain in female athletes. Clinical Biomechanics, 25(7), 700-707. https://doi.org/10.1016/j.clinbiomech.2010.04.001.

Myer, G. D., Ford, K. R., Stasi, Di S. L., Foss, B. K. D., Micheli, L. J. \& Hewett, T. E. (2015) High knee abduction moments are common risk factors for patellofemoral pain (PFP) and anterior cruciate ligament (ACL) injury in girls: Is PFP itself a predictor for subsequent ACL injury? British Journal of Sports Medicine, 49(2), 118-122. https://doi.org/10.1136/bjsports-2013-092536.

Nejati, P., Forogh, B., Moeineddin, R., Baradaran, H. R., \& Nejati, M. (2011).
Patellofemoral pain syndrome in Iranian female athletes. Acta Medica Iranica, 49(3), 169-172. https://doi.org/10.1007/s00167-013-2759-6.

Peluso, M. A. M., \& Andrade, de L. H. S. G. (2005). Physical activity and mental health: The association between exercise and mood. Clinics, 60(1), 61-70. https://doi.org/10.1590/S1807-59322005000100012.

Powers, C. M., Bolgla, L. a, Callaghan, M. J., Collins, N., \& Sheehan, F. T. (2012). Patellofemoral pain: Proximal, distal, and local factors, 2nd International research retreat. Journal of Orthopaedic \& Sports Physical Therapy, 42(6), A1-A54. https://doi.org/10.2519/jospt.2012.0301.

Powers, C., Perry, J., Hsu, A., \& Hislop, H. (1997). Are patellofemoral pain and quadriceps strength associated with locomotor function? Physical Therapy, 77(10), 1063-74.

Rathleff, M. S. (2016). Patellofemoral pain during adolescence: Much more prevalent than appreciated. British Journal of Sports Medicine, 50(14), 831-833. https://doi.org/10.1136/bjsports-2016-096328.

Rathleff, C. R., Baird, W. N., Olesen, J. L., Roos, E. M., Rasmussen, S., \& Rathleff, M. S. (2013). Hip and knee strength is not affected in 12-16 year old adolescents with patellofemoral pain - a cross-sectional population-based study. PLoS One, 8(11), 1-8. https://doi.org/10.1371/journal.pone.0079153.

Rathleff, M. S., Rathleff, C. R. Olesen, J. L. Rasmussen, S., \& Roos, E. M. (2016). Is knee pain during adolescence a self-limiting condition? Prognosis of patellofemoral pain and other types of knee pain. The American Journal of Sports Medicine, 44(5), 1165-1171. https://doi.org/10.1177/0363546515622456.

Rathleff, M. S., Roos, E. M., Olesen, J. L., \& Rasmussen, S. (2015). Exercise during school hours when added to patient education improves outcome for 2 years in adolescent patellofemoral pain: A cluster randomised trial. British Journal of Sports Medicine, 49(6), 406-412. https://doi.org/10.1136/bjsports-2014-093929.

Roos, E. M., \& Lohmander, L. S. (2003). The knee injury and osteoarthritis outcome score (KOOS): From joint injury to osteoarthritis. Health and Quality of Life Outcomes, 64(1). https://doi.org/10.1186/1477-7525-1-64.

Roos, E. M., Roos, H. P., Lohmander, L. S., Ekdahl, C., \& Beynnon, B. D. (1998). Knee injury and osteoarthritis outcome score (KOOS)-development of a selfadministered outcome measure. Journal of Orthopaedic \& Sports Physical Therapy, 28(2), 88-96. https://doi.org/10.2519/jospt.1998.28.2.88.

Stathopulu, E., \& Baildam, E. (2003). Anterior knee pain: A long-term follow-up. Rheumatology, 42(2), 380-382. https://doi.org/10.1093/rheumatology/keg093.

Sullivan, G. M., \& Feinn, R. (2012). Using effect size-or why the p value is not enough. Journal of Graduate Medical Education, 4(3), 279-282. https://doi.org/ 10.4300/JGME-D-12-00156.1.

Tállay, A., Kynsburg, A., Tóth, S., Szendi, P., Pavlik, A., Balogh, E., ... Berkes, I. (2004). Prevalence of patellofemoral pain syndrome. Evaluation of the role of biomechanical malalignments and the role of sport activity. Orvosi Hetilap, 145(41), 2093-2101.

Utting, M. R., Davies, G., \& Newman, J. H. (2005). Is anterior knee pain a predisposing factor to patellofemoral osteoarthritis? The Knee, 12(5), 362-365. https://doi.org/10.1016/j.knee.2004.12.006.

Valovich McLeod, T. C., Bay, R. C., Parsons, J. T., Sauers, E. L., Snyder, A. R., McLeod, T. C. V., ... Snyder, A. R. (2009). Recent injury and health-related quality of life in adolescent athletes. Journal of Athletic Training, 44(6), 603-610. https:// doi.org/10.4085/1062-6050-44.6.603.

Van de Graaf, V. A., Wolterbeek, N., Scholtes, V. A. B., Mutsaerts, E. L. A. R., \& Poolman, R. W. (2014). Reliability and validity of the IKDC, KOOS, and WOMAC for patients with meniscal injuries. The American Journal of Sports Medicine, 42(6), 1408-1416. https://doi.org/10.1177/0363546514524698.

Waiteman, M. C., Coura, M. B., Araújo, C. G. A., Briani, R. V., De Oliveira Silva, D., \& de Azevedo, F. M. (2017). Comparison of the level of patellofemoral pain, physical activity, and quality of life between female and male adolescents. Scientia Medica, 27(1). https://doi.org/10.15448/1980-6108.2017.1.25250.

Witvrouw, E., Callaghan, M. J., Stefanik, J. J., Noehren, B., Bazett-Jones, D. M., Willson, J. D., ... Crossley, K. M. (2014). Patellofemoral pain: Consensus statement from the 3rd International patellofemoral pain research retreat held in Vancouver, September 2013. British Journal of Sports Medicine, 48(6), 411-414. https://doi.org/10.1136/bjsports-2014-093450.

Witvrouw, E., Lysens, R., Bellemans, J., Cambier, D., \& Vanderstraeten, G. (2000). Intrinsic risk factors for the development of anterior knee pain in an athletic population. A two-year prospective study. The American Journal of Sports Medicine, 28(4), 480-489. 